\title{
Chronic Obstructive Pulmonary Disease-Specific Gene Expression Signatures of Alveolar Macrophages as well as Peripheral Blood Monocytes Overlap and Correlate with Lung Function
}

\author{
Szilard Poliska ${ }^{a, c}$ Eszter Csanky ${ }^{d, f}$ Attila Szanto $^{a}$ Istvan Szatmaria \\ Bertalan Mesko ${ }^{a, c}$ Lajos Szeles ${ }^{a, b}$ Balazs Dezso ${ }^{e}$ Beata Scholtz ${ }^{a, c}$ \\ Janos Podanig lain Kilty ${ }^{\mathrm{h}}$ Laszlo Takacs ${ }^{\mathrm{i}}$ Laszlo Nagy $^{\mathrm{a}-\mathrm{c}}$ \\ a Department of Biochemistry and Molecular Biology and ${ }^{b}$ Apoptosis and Genomics Research Group, Hungarian \\ Academy of Sciences, Research Center for Molecular Medicine, ${ }^{C}$ Clinical Genomics Center, ${ }^{d}$ Department of \\ Pulmonology, and ' Department of Pathology, Medical and Health Science Center, University of Debrecen, \\ Debrecen, and ${ }^{\mathrm{f} D e p a r t m e n t}$ of Pulmonology, Semmelweis Health Care Center, Miskolc, and ${ }^{9}$ Biological Institute,

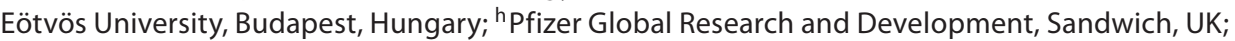 \\ 'Biosystems International SAS, Evry, France
}

\section{Key Words}

Alveolar macrophages - Chronic obstructive pulmonary disease $\cdot$ Disease-specific genes $\cdot \mathrm{FEV}_{1} \cdot$ Lung function • Microarray $\cdot$ Monocytes

\section{Abstract \\ Background: Chronic obstructive pulmonary disease (COPD) is a chronic inflammatory disease characterized by progressive airflow limitation and significant extrapulmo- nary (systemic) effects that lead to co-morbid conditions, though the pathomechanism of COPD is largely undeter- mined. Alveolar macrophages (AM) derived from peripheral monocytes (MO) appear to play a key role in initiating and/ or sustaining disease progression. Objectives: To identify disease- and cell type-specific gene expression profiles and potential overlaps in those in order to diagnose COPD, char- acterize its progression and determine the effect of drug treatment. Method: Global gene expression analysis was used for primary screening in order to obtain expression sig- natures of AMs and circulating MOs of COPD patients and healthy controls. The results of microarray analyses of AMs}

( 20 controls and 26 COPD patients) and MOs ( 16 controls and 22 COPD patients) were confirmed and validated by realtime quantitative polymerase chain reaction. Results: We have identified gene sets specifically associated with COPD in $\mathrm{AMs}$ and $\mathrm{MO}$. There were overlapping genes between the two cell types. Our data also show that COPD-specific gene expression signatures in AMs and MOs correlate with percent of predicted FEV ${ }_{1}$. Conclusion: Disease-specific and overlapping gene expression signatures can be defined in lung-derived macrophages and also in circulating monocytes. Some of the validated expression changes in both cell types correlate with lung function and therefore could serve as biomarkers of disease progression.

Copyright $\odot 2011$ S. Karger AG, Basel

\section{Introduction}

Chronic obstructive pulmonary disease (COPD), characterized by slowly progressing and mostly irreversible development of airflow limitation, is an increasing global health problem, which is predicted to become the

\section{KARGER}

Fax +4161306 1234

E-Mail karger@karger.ch

www.karger.com
C 2011 S. Karger AG, Basel

0025-7931/11/0816-0499\$38.00/0

Accessible online at:

www.karger.com/res
Laszlo Nagy

Department of Biochemistry and Molecular Biology

Medical and Health Science Center, University of Debrecen

Life Science Building LSB 3.210, Egyetem ter 1, HU-4010 Debrecen (Hungary)

Tel. +36 52416 432, E-Mail nagyl@ med.unideb.hu 
third most common cause of death and the fifth most common cause of disability in the world by 2020 [1]. It is accompanied by small-airway obstruction and loss of lung elasticity. The molecular mechanisms leading to the development and progression of the disease are poorly understood; consequently, effective treatment is not yet available. There are several risk factors for COPD, such as life and work circumstances, environmental pollution and aging, but the main cause is cigarette smoking. Only $15-20 \%$ of smokers develop COPD, suggesting that differential responsiveness to cigarette smoking is likely to be an important factor in its pathogenesis [2].

Clinically, COPD is characterized by inflammation of the epithelium of the small airways, and it most commonly occurs in patients with chronic bronchitis or emphysema [3], which is defined as enlargement of the distal airspaces and mucus hypersecretion $[1,4,5]$. The most accepted theory of the pathogenesis of COPD is that cigarette smoke and other irritants induce inflammation in the lung causing an inflammatory response that leads to the destruction of lung tissue. It is initiated by activation of epithelial cells of the lung and abnormal migration of various inflammatory cells [6-8].

Beside neutrophils [9] and lung-specific dendritic cells [10], alveolar macrophages (AMs) are believed to be one of the most important cells in the pathogenesis of COPD. They play a major role in maintaining and controlling the inflammatory process in COPD. The number of macrophages is markedly increased in the lung parenchyma and alveolar space of smokers and diseased patients [11, 12]. There is also a higher rate of monocyte (MO) recruitment from the peripheral blood [13]. Importantly, oxidative stress and cigarette smoke activate macrophages that produce various factors and inflammatory agents such as IL- 8 , leukotriene $\mathrm{B}_{4}$ and GRO- $\alpha$, which can contribute to neutrophil and T-cell activation as well as airway obstruction $[14,15]$. It seems that MO-derived AMs have a central role in controlling and maintaining the inflammatory process by producing pro-inflammatory factors $[7,16]$.

Previous studies have already examined global gene expression patterns of COPD or the smoking effect on monocyte-derived macrophages of COPD patients [17]. Total lung tissue from patients with severe emphysema $[18,19]$ and smokers $[20]$ was examined using microarray techniques, and sets of genes were identified to discriminate healthy from diseased tissue. Lung epithelial cells and AMs were also examined to determine which genes show differential expression between COPD and control patients [21-25].
The objectives of our study were (1) to expand and validate the list of genes associated with smoking-induced COPD in AMs; (2) to find and validate potential biomarkers in peripheral blood MOs that reflect COPD-specific gene expression patterns identified in AMs, and (3) to correlate gene expression patterns with disease parameters.

Such an approach may provide insights into the pathogenesis and progression of COPD, and may also identify potential peripheral biomarkers.

\section{Materials and Methods}

\section{Patient Recruitment}

The Research Ethics Committee of the University of Debrecen Medical and Health Science Center approved the clinical protocol and the study. All healthy and diseased individuals participating in this study were recruited from Eastern Hungary (Caucasians), and all patients provided written informed consent.

Inclusion and exclusion criteria were defined before obtaining samples from COPD patients and healthy controls. All subjects were between 40 and 65 years old. In COPD patients, percent of predicted $\mathrm{FEV}_{1}\left(\mathrm{FEV}_{1} \%\right)$ was $<80 \%$ and $\mathrm{FEV}_{1}$ to percent of predicted FVC (FVC\%) was $<70 \%$; in control patients, $\mathrm{FEV}_{1} \%$ was $\geq 80 \%$ and $\mathrm{FEV}_{1} / \mathrm{FVC} \%$ was $\geq 70 \%$. Online supplementary material (www.karger.com/doi/10.1159/000324297) is provided for additional information.

\section{AM and Peripheral Blood MO Collection}

Bronchoalveolar lavage fluid (BALF) was sampled during fiberoptic bronchoscopy. AMs were separated by Percoll (Amersham Biosciences) gradient centrifugation. Total cell numbers were determined using a hemocytometer. Differential cell counts were assessed on hematoxylin-eosin-stained cytospin slides before and after the gradient separation. Over 95\% AM purity was reached after separation [26-28]. The range, mean and SD were 95-98 and 96.6 $\pm 1.3 \%$ in AM; $0.5-4$ and $1.7 \pm 1 \%$ in lymphocytes, and $1-2.4$ and $0.8 \pm 0.6 \%$ in neutrophils, respectively.

Heparin-treated venous blood $(50 \mathrm{ml})$ was collected from healthy controls and patients, respectively. MOs were separated by a two-step procedure: first peripheral blood MOs were separated by Ficoll gradient centrifugation, and then MOs were separated by positive selection using anti-CD14-conjugated microbeads (>98\% MOs; VarioMACS, Miltenyi Biotec). Details are described in the online supplementary material.

\section{RNA and Microarray Processing}

Total RNA was extracted from AMs and peripheral blood MOs using the RNeasy Mini Kit (Qiagen). RNA integrity was checked on Agilent Bioanalyser 2100 (Agilent Technologies), and NanoDrop ND-1000 was used to determine the concentration. Affymetrix HG-U133A arrays (Affymetrix) containing 22,283 probe sets were used to perform gene expression analysis.

Complementary DNA (cDNA) was generated from $5 \mu \mathrm{g}$ of total RNA, using the SuperScript choice system (Invitrogen). 
Table 1. Parameters and characteristics of the COPD patients and controls

\begin{tabular}{|c|c|c|c|c|c|c|}
\hline \multirow[t]{2}{*}{ Parameter } & \multicolumn{2}{|c|}{ AM exploratory cohort } & \multicolumn{2}{|c|}{ AM validation cohort } & \multicolumn{2}{|c|}{ MO validation cohort } \\
\hline & $\begin{array}{l}\text { control } \\
(\mathrm{n}=5)\end{array}$ & $\begin{array}{l}\text { COPD } \\
(n=5)\end{array}$ & $\begin{array}{l}\text { control } \\
(n=20)\end{array}$ & $\begin{array}{l}\text { COPD } \\
(n=26)\end{array}$ & $\begin{array}{l}\text { control } \\
(n=16)\end{array}$ & $\begin{array}{l}\text { COPD } \\
(n=22)\end{array}$ \\
\hline Males/females & $5 / 0$ & $5 / 0$ & $19 / 1$ & $24 / 2$ & $13 / 3$ & $21 / 1$ \\
\hline Race & Caucasian & Caucasian & Caucasian & Caucasian & Caucasian & Caucasian \\
\hline Age, years & $44.8 \pm 7.6$ & $52.8 \pm 6.6$ & $53.7 \pm 13.7$ & $57.8 \pm 9.4$ & $53.4 \pm 7.6$ & $57.5 \pm 9.2$ \\
\hline Range & $40-58$ & $48-63$ & $42-64$ & $43-65$ & $47-65$ & $44-65$ \\
\hline \multicolumn{7}{|l|}{ Smoking status } \\
\hline Current & 5 & 5 & 17 & 22 & 14 & 19 \\
\hline Former & & & 3 & 4 & 2 & 3 \\
\hline Pack-years & $31.26 \pm 25.9$ & $40.2 \pm 17.5$ & $29.1 \pm 14.3$ & $35.9 \pm 18.1$ & $32.1 \pm 20.9$ & $35.7 \pm 17.2$ \\
\hline Range & $15-58$ & $29-70$ & $15-60$ & $16-76$ & $20-78$ & $15-75$ \\
\hline Duration of smoking, years & $19.4 \pm 12.26$ & $30.2 \pm 10$ & $30.9 \pm 14.1$ & $34.3 \pm 11.8$ & $27.4 \pm 13.2$ & $36.1 \pm 10.5$ \\
\hline Range & $9-39$ & $15-42$ & $9-43$ & $12-47$ & $23-49$ & $25-45$ \\
\hline FVC\%* & $90.1 \pm 6$ & $74.5 \pm 4.1$ & $92.6 \pm 8.9$ & $71.5 \pm 7.9$ & $96 \pm 14.1$ & $65.1 \pm 12.4$ \\
\hline Range & $82-96.2$ & $65.8-79$ & $81-116$ & $42-79$ & $81-103$ & $36-73$ \\
\hline $\mathrm{FEV}_{1} \%^{*}$ & $88.8 \pm 8.1$ & $55.8 \pm 14.8$ & $93.2 \pm 8.6$ & $63.1 \pm 14.3$ & $96.8 \pm 12.3$ & $70.2 \pm 7$ \\
\hline Range & $80.8-100.3$ & $36.6-76$ & $83-112$ & $32.5-78$ & $83-109$ & $31-78$ \\
\hline BMI & $26.8 \pm 3.6$ & $23.5 \pm 2.7$ & $26.2 \pm 2.6$ & $25.2 \pm 3.7$ & $27.6 \pm 3.8$ & $26.2 \pm 5.4$ \\
\hline Range & $24.1-32.28$ & $20.07-26.8$ & $20.1-35$ & $18.6-31.1$ & $23.8-35.1$ & $18.7-36.75$ \\
\hline $\mathrm{CRP}, \mathrm{mg} / \mathrm{l}^{*}$ & $2.3 \pm 1.9$ & $15.7 \pm 11.3$ & $2.6 \pm 1.4$ & $6.3 \pm 4.3$ & $2.6 \pm 1.7$ & $6.4 \pm 4.7$ \\
\hline Range & $0.5-3.6$ & $2.1-18$ & $0.33-5.1$ & $1.16-17$ & $0.5-6.2$ & $1.19-4.79$ \\
\hline
\end{tabular}

Data are presented as means $\pm \mathrm{SD}$ and ranges. ${ }^{*} \mathrm{p}<0.05$, COPD patients vs. controls (Mann-Whitney U test).

Biotin-labeled cRNA was synthesized using the BioArray ${ }^{\mathrm{TM}}$ HighYield $^{\mathrm{TM}}$ RNA Transcript Labeling Kit (T7) (ENZO Life Sciences), and $20 \mu \mathrm{g}$ of labeled cRNA samples were hybridized and scanned by EMBL Genomics Core Facility. BALF samples were hybridized separately, but in the case of MOs RNA was mixed from 5 controls and 5 COPD patients, respectively.

\section{Microarray Data Analysis}

AM and MO microarrays were analyzed in separate experiments using GeneSpring 7.3 software (Agilent Technologies). Affymetrix data files were directly imported into GeneSpring using the GCRMA algorithm, and median normalization was performed. First, we determined the list of genes that showed a ratio of change in gene expression of at least \pm 1.5 -fold compared to the median of each sample. Then, based on this list we performed separate statistical analyses (Mann-Whitney non-parametric test) for each gene to identify differentially expressed genes over the probability level $p<0.05$. We are aware of the cumulative effect of type I errors in such multiple situations; therefore, these tests served the purpose of selecting genes for further study rather than formal tests of significance. Microarray data were submitted to Gene Expression Omnibus (GEO), accession number GSE16972.

TaqMan mRNA Analysis by Real-Time Quantitative

Polymerase Chain Reaction

In order to confirm the results of the microarray analysis, we used TaqMan Low Density Arrays (TLDAs), a real-time quanti- tative polymerase chain reaction (RT-qPCR) platform, and individual gene expression assays (Applied Biosystems). Probes and primers were taken from the Roche Universal Probe Library system (Roche) in order to confirm the expression of common genes in AMs and MOs. Reactions were run in the ABI Prism HT 7900 machine. Relative gene expression levels were calculated by $\Delta \Delta \mathrm{Ct}$ method with GAPDH as the internal control. Statistical analysis was performed by GraphPad Prism software. A non-parametric test (Mann-Whitney U test) was used to identify significant differences between the control and COPD groups for each gene for the above-described purposes. Statistical significance was defined as $\mathrm{p}<0.05$. Pearson correlation coefficients were calculated between gene expression data and $\mathrm{FEV}_{1} \%$ values.

\section{Canonical Variate Analysis}

Separation between predefined groups of objects is best revealed by canonical variate analysis (CVA). It is used to determine whether the groups of controls and COPD patients are separable in the multidimensional space spanned by the genetic variables, and if so, which gene subsets have the best discriminatory power. The results of CVA are the so-called canonical scores obtained from the canonical functions derived through eigenanalysis, which serve as coordinates of observations in the canonical space. Details about CVA are included in the online supplementary material. 


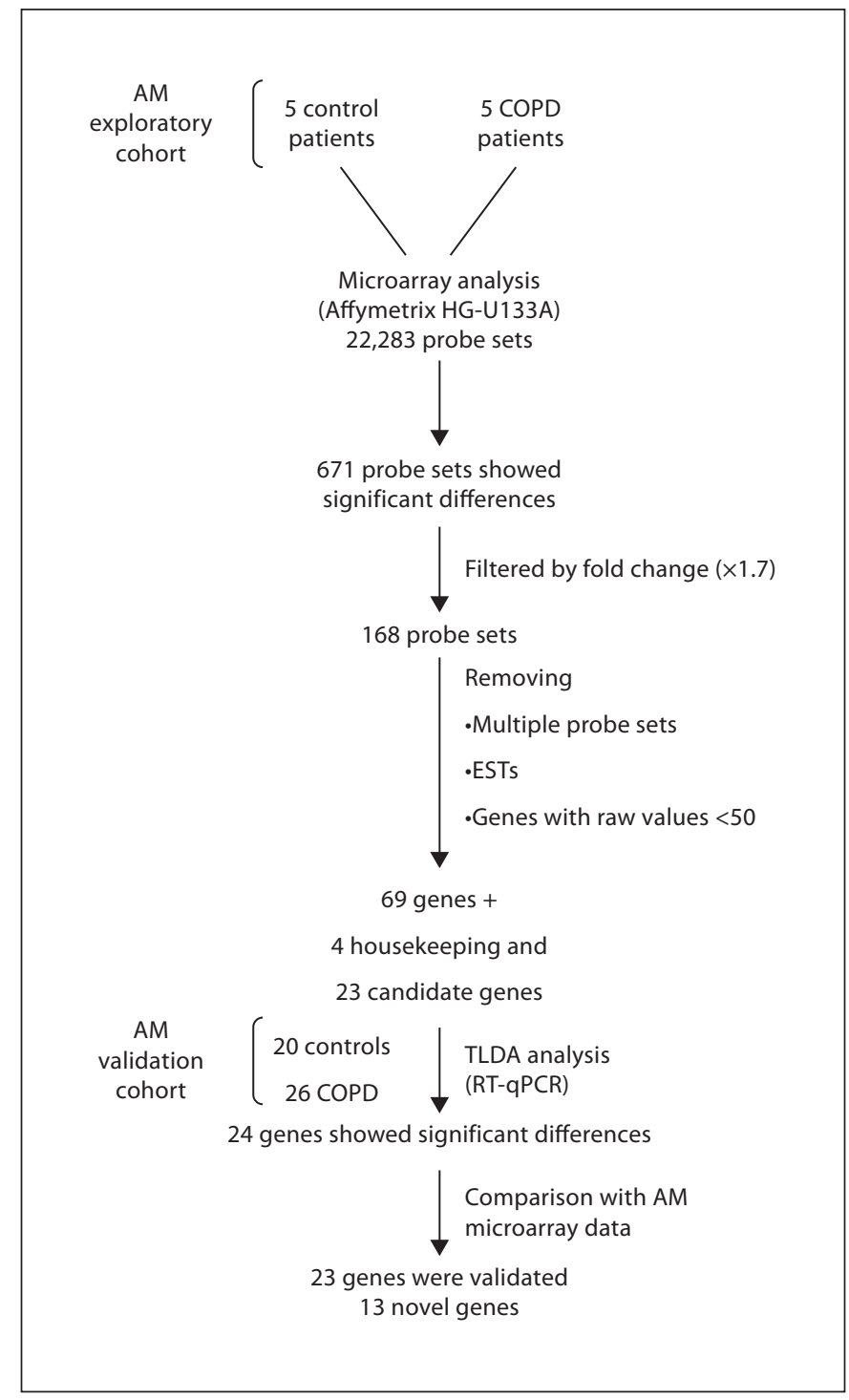

Fig. 1. Experimental design and microarray data analysis. AMs were collected from healthy controls and COPD patients using fiberoptic bronchoscopy. After RNA isolation, samples were hybridized to Affymetrix HG-U133A GeneChips. Microarray data were analyzed using GeneSpring 7.3 software. 22,283 probe sets were tested by filter on expression level option, 671 probe sets showed significant differences, of which 168 probe sets showed at least 1.7-fold changes between controls and COPD patients. Multiple probe sets expressed sequence tags and genes with raw values $<50$ were removed resulting in a list of 69 genes; 96 genes, including these 69 genes, were analyzed on TLDAs; 24 of them showed significant differences, and 23 were validated. EST $=$ Expressed sequence tags.

\section{Results}

Exploratory Microarray Analyses of AMs in BALF

AMs were collected from 5 controls and 5 COPD patients, with all of them being smokers. COPD patients were in stage 2-3 according to the Global Initiative for Chronic Obstructive Lung Disease. The control and COPD groups were homogenous regarding age and smoking habits, but differed in lung function parameters (table 1).

AMs of 5 control and 5 COPD patients were subjected to global gene expression analysis using microarrays. This analysis resulted in a list of 671 probe sets representing 389 annotated genes, which showed significant correlation with the disease. Hierarchical cluster analysis of these 671 probe sets separated healthy controls from COPD patients (online suppl. fig. 1). Our COPD-specific expression signature included genes that have previously been associated with COPD, such as CYP1B1 and PLA2G7 $[21,23]$, as well as CCL2, IL-8, IL-1 $\beta$ and SPP1, which have been ascribed an involvement in immune responses and cell migration, or the stimulation of airway epithelial cells $[14,18,20]$. This validated both the patient cohort and our approach, and suggested that our novel findings can complement already existing markers and link additional genes and pathways to COPD.

\section{Novel Candidate Genes Identified by RT-qPCR in}

$A M s$ in $B A L F$

In order to confirm and validate our microarray results, the gene expression levels of 96 selected genes were measured in the BALF samples of a new cohort of 46 patients including 26 COPD patients and 20 healthy controls. All individuals were active smokers or ex-smokers in the validation set (table 1).

TLDA was used to determine COPD-associated genes in AMs separated from BALF. They contained 96 genes, including 4 housekeeping genes, 23 candidate genes obtained from the literature $[18,22,23]$ and 69 genes chosen from our exploratory microarray experiment. The list of 69 genes was created by filtering the 671 probe sets that correlated significantly with the disease in the exploratory microarray experiment by \pm 1.7 -fold change compared to the median of all samples and removing multiple probe sets, expressed sequence tags and genes with raw values $<50$ (fig. 1).

Twenty-four genes showed significantly different expression patterns between controls and COPD patients. Twenty-three genes changed in the same direction both on the microarrays and in the RT-qPCR experiment 
Fig. 2. Comparison of AM microarray and RT-qPCR validation data. Fold differences were determined by microarray (HGU133A) and RT-qPCR in AMs (empty bars represent RT-qPCR; filled bars represent microarray data). These 23 genes showed statistically significantly different expression levels between COPD patients and controls (Mann-Whitney U test) and were thus validated.

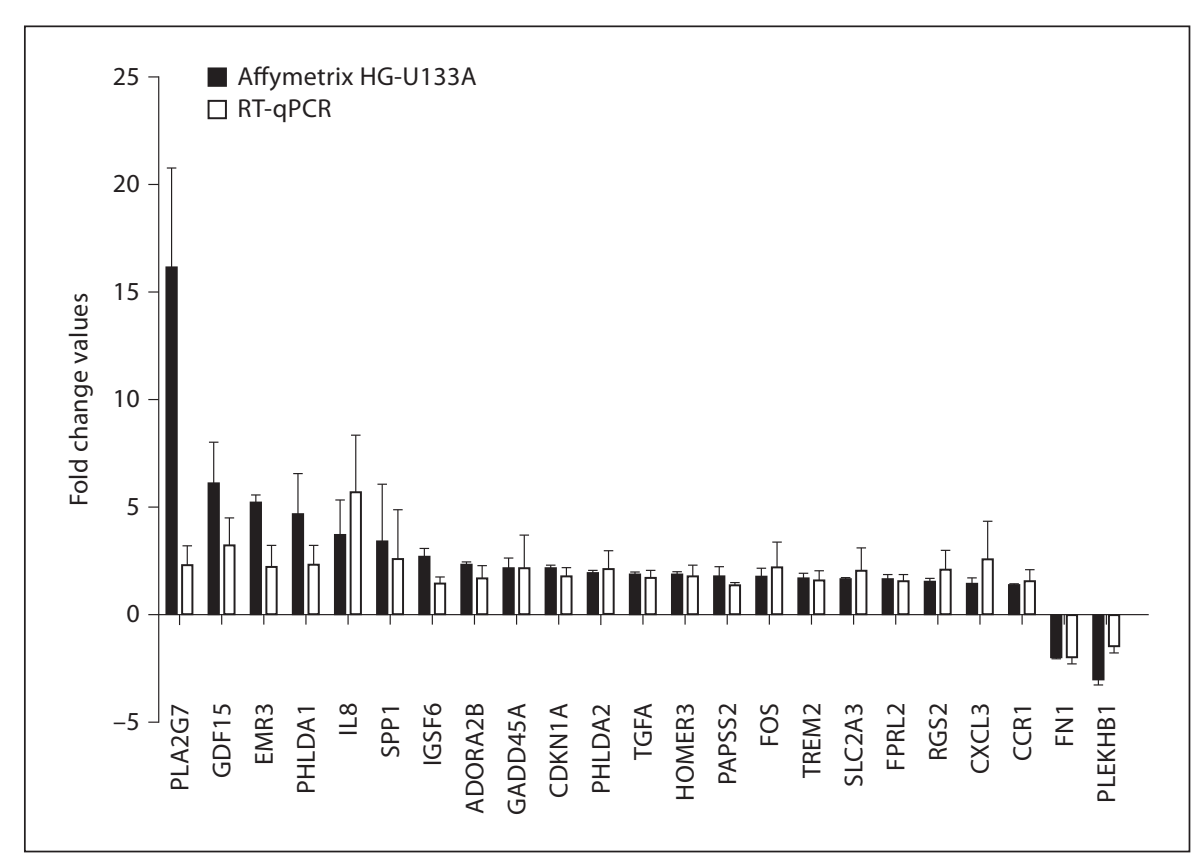

(fig. 2). Five genes previously reported in other microarray studies (IL-8, CDKN1A, FOS, PLA2G7 and SPP1) [18, $21-23,29$ ] were confirmed in this experiment. We also found genes with already established roles in inflammatory processes of the lung, including ADORA2B, FN1 and TGF- $\alpha$ [30-34]. Thirteen novel genes were found to be related to inflammatory processes of COPD. These belong to the functional categories immune responses (CCR1 and TREM2), apoptosis (GADD45A, PHLDA1 and PHLDA2) and signal transduction (EMR3, GDF15, FPRL2 and HOMER3), suggesting that these functions are affected by the disease, while IGSF6, PAPSS2, PLEKHB1 and SLC2A 3 were unclassified (fig. 3a-d).

We performed an independent statistical approach (CVA) using these 23 validated genes in order to test whether this gene set can indeed separate COPD patients from controls (fig. 3e). Canonical correlation for this gene set was $0.8\left(\chi^{2}=34.25\right.$, d.f. $=20$, significant at $p=0.05$, Wilks' $\lambda=0.365)$, which suggests that such a set can differentiate between controls and COPD patients.

\section{Identifying COPD-Specific Gene Expression \\ Signatures in Peripheral Blood MOs}

Next we decided to address our attention to peripheral MOs and compare changes in their expression between COPD and control samples. MOs were separated from peripheral blood samples that were collected simultaneously and pooled separately from 5 controls and also from 5 COPD patients following RNA isolation. Microarray analysis was performed on this new sample set, and results revealed a list of 555 probe sets with 356 annotated genes that showed at least 1.5 -fold change differences between COPD patients and controls in peripheral blood MOs. We compared that list to the AM microarray result, resulting in a list of 54 probe sets representing 35 annotated genes (fig. 4a).

We sought to validate genes commonly expressed in AMs and peripheral blood MOs by measuring the expression levels of these 35 genes using RT-qPCR.

In a new cohort consisting of 22 COPD patients and 16 controls, of whom 13 COPD patients and 7 controls were newly recruited individuals, MO RNA samples were examined for this validation (table 1).

Using RT-qPCR, 5 of the 35 genes that were significantly different between COPD patients and controls were validated. ADAM10, GK, IFRD1, PHLDA1 and SEC14L1 had higher expression levels in diseased patients (fig. 4b). Again, CVA showed that the combination of these 5 genes separated fairly well the COPD patients and controls (canonical correlation was $0.62, \chi^{2}=$ 14.75 , d.f. $=5$, significant at $\mathrm{p}=0.05$, Wilks' $\lambda=0.617$; fig. 4c).

Remarkably, these experiments confirmed our hypothesis that peripheral MOs also carry a COPD-related gene expression pattern and, moreover, that there is some overlap between AM and MO COPD signatures. 


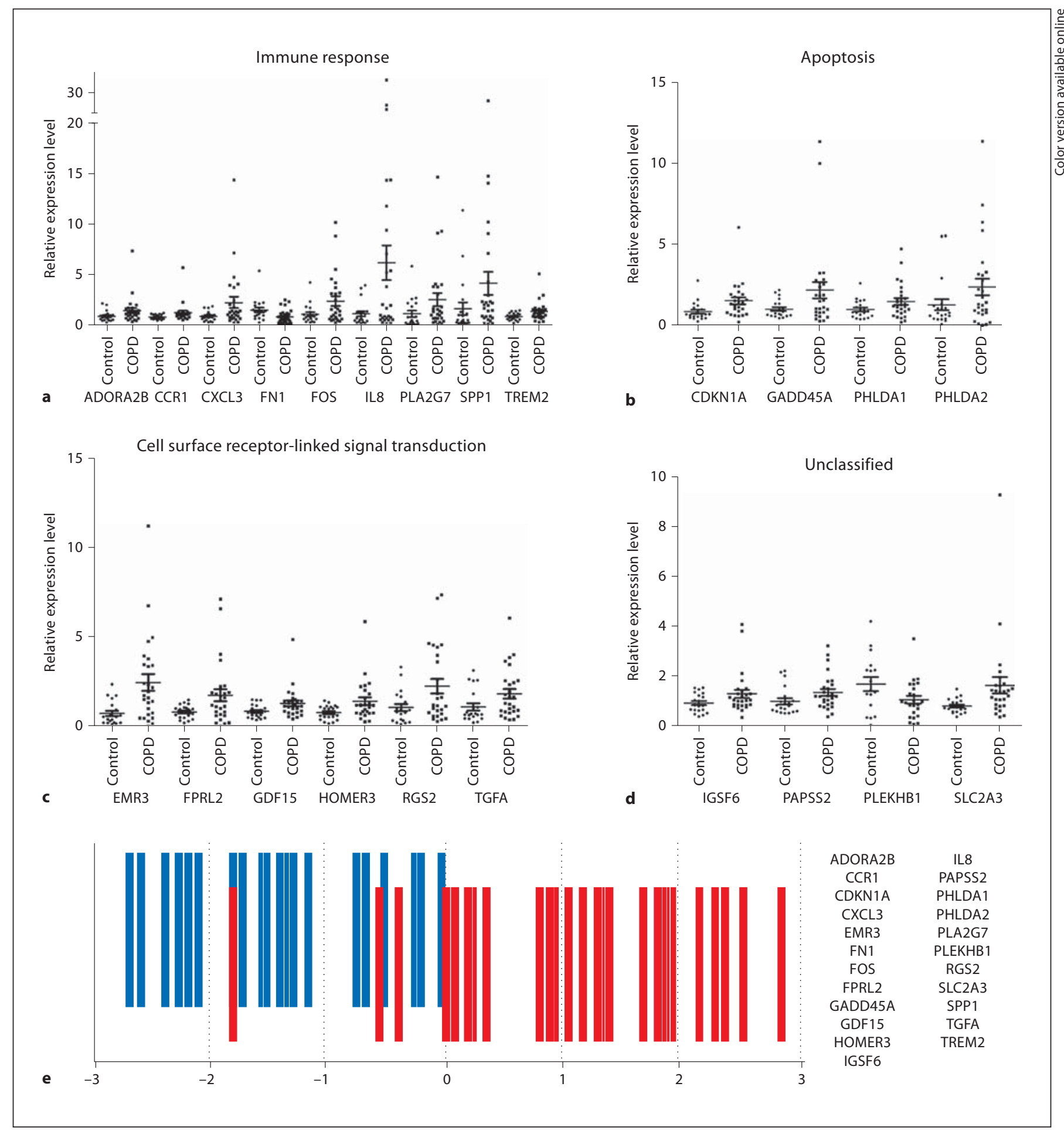

Fig. 3. Individual values of RT-qPCR-validated COPD-related genes and CVA. a-d Validation of differential gene expression data by RT-qPCR. The individual values of RT-qPCR of the indicated genes from AMs are plotted. Relative expression levels are shown normalized to GAPDH. All of the 23 genes showed statistically significant differences in expression levels between controls and COPD patients (Mann-Whitney U test). e CVA of the validated 23 genes that showed significant differences between COPD patients and controls in AM samples separated COPD patients and healthy controls in the AM validation cohort. Red (dark grey in the printed version) bars represent COPD, and blue (light grey in the printed version) bars represent healthy controls. Numbers on the $\mathrm{x}$-axis are spherized canonical scores of objects on the single canonical variate. 


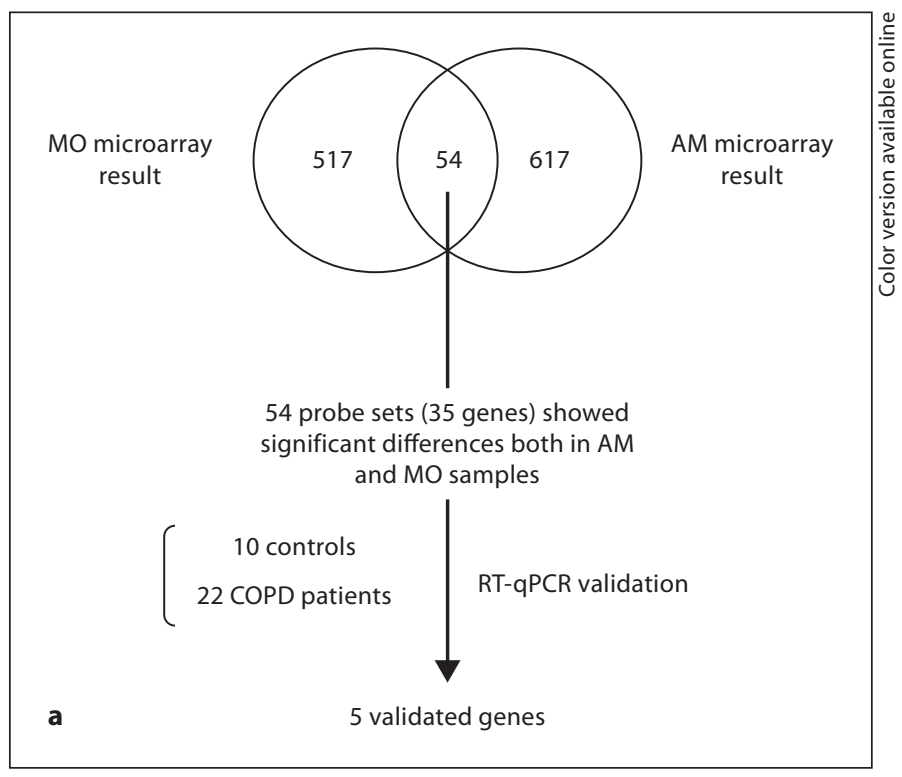

Fig. 4. Experimental design of the comparison of AM and MO microarray data, and validation of $\mathrm{MO}$ results by RT-qPCR and CVA. a Venn diagram of gene expression patterns of commonly expressed probe sets between AMs and MOs and probe sets expressed in a COPD-specific manner in the two cell types using HG-U133A microarray data; 54 probe sets (representing 35 annotated genes) overlapped between AMs and MOs, of which 5 genes were validated using RT-qPCR. b The individual values of RT-qPCR of the indicated genes from peripheral MOs of patients of the cross-validation set are plotted. Relative expression levels are shown normalized to GAPDH. All of the 5 genes showed statistically significant differential expression between controls and COPD patients (Mann-Whitney U test). c CVA of these 5 genes separated the COPD patients from controls in the $\mathrm{MO}$ validation cohort. Red (dark grey in the printed version) bars represent COPD patients, and blue (light grey in the printed version) bars represent healthy controls. Numbers on the $\mathrm{x}$-axis are spherized canonical scores of objects on the single canonical variate.

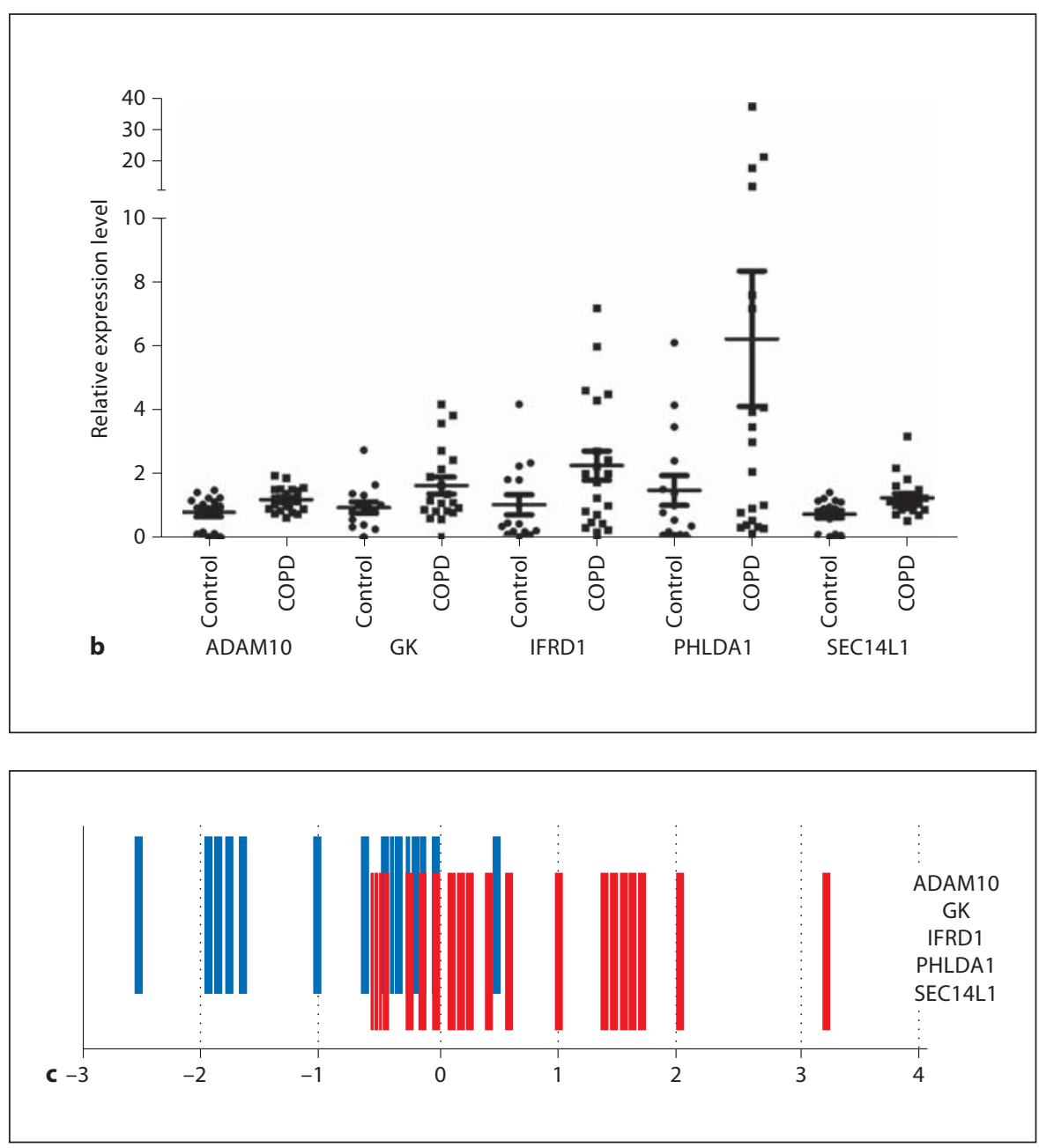




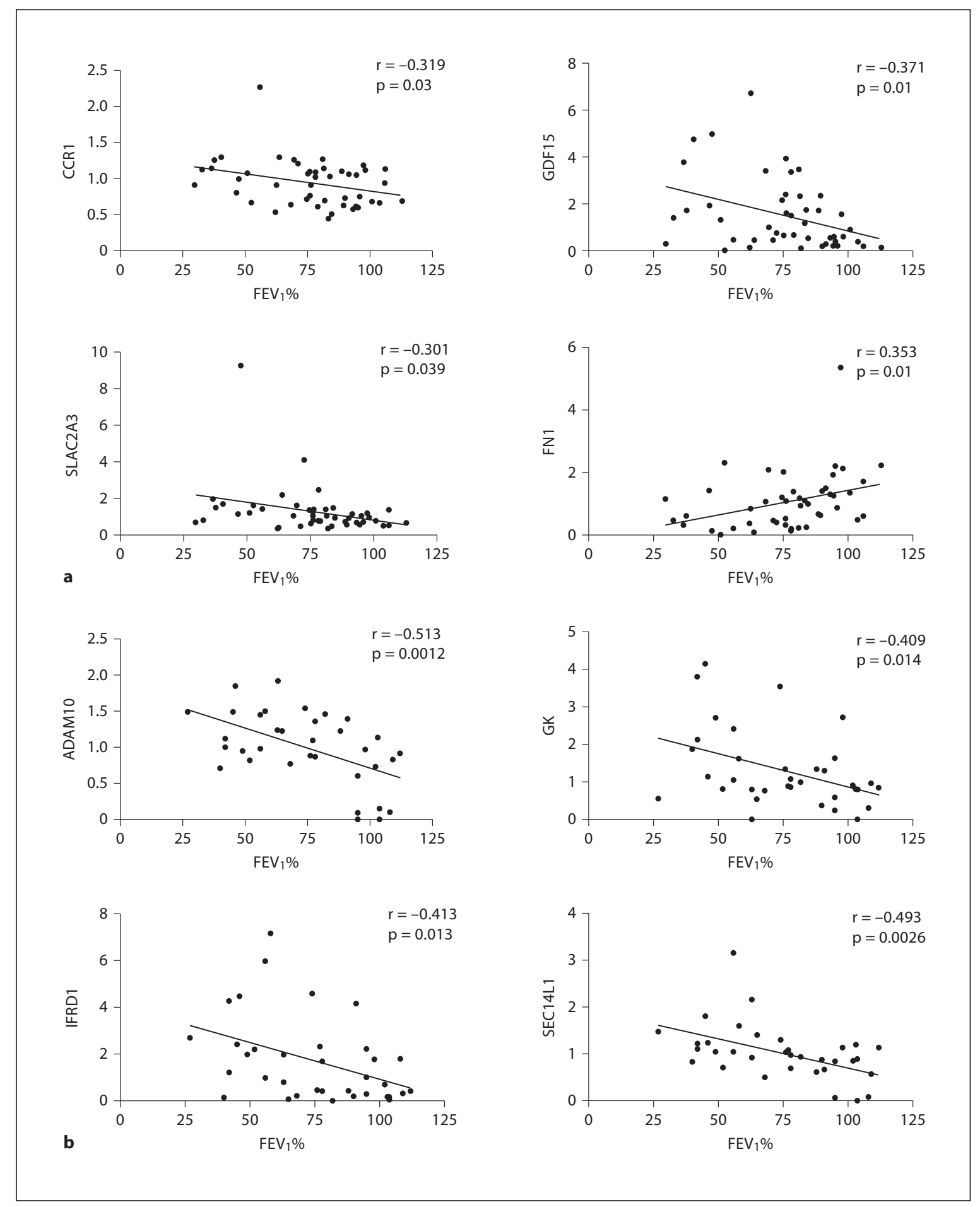

Fig. 5. Gene expression signatures correlate with $\mathrm{FEV}_{1} \%$. COPD-specific gene expression signatures of AMs (notably CCR1, FN1, GDF15 and SLC2A3; a) and MOs (such as ADAM10, GK, IFRD1 and SEC14L1; b) correlate with $\mathrm{FEV}_{1} \%$. Pearson correlation was used; statistical significance of correlations was tested at $\mathrm{p}<0.05$. 
Correlation between Lung Function and Gene

Expression Data

A key issue in identifying biomarkers in general and disease-specific expression signatures in particular is the ability to correlate these with clinical parameters relevant in the disease. In the case of COPD, the key clinical feature is a lung function decrease measured by lung function tests. Therefore, as the next step of our studies, the possible correlation between $\mathrm{FEV}_{1} \%$ values and expression data of the RT-qPCR-validated genes was examined. We calculated Pearson correlation between lung function parameter $\mathrm{FEV}_{1} \%$ and all the 23 genes $[23,35]$ and found that higher expression of CCR1, GDF15 and SLC2A3 from the AM validation set obtained from BALF samples correlated with lower $\mathrm{FEV}_{1} \%$ values. However, higher expression of FN1 correlated with increased values of $\mathrm{FEV}_{1} \%$ (fig. 5a).

In the peripheral $\mathrm{MO}$ validation set, ADAM10, GK, IFRD1 and SEC14L1, but not PHLDA1, were correlated with lower $\mathrm{FEV}_{1} \%$ values (fig. $5 \mathrm{~b}$ ).

These data indicated that gene expression changes can be correlated with lung function changes both in AMs and probably most intriguingly in peripheral blood MOs.

\section{Discussion}

Especially in chronic diseases, it is of critical importance to identify markers of a disease state and its progression as well as cell types affected by this disease. Recent developments in genomic technologies, including the extensive use of microarray technology, provided an opportunity to perform global gene expression analyses to compare tissue samples or distinct cell types in order to establish correlations between disease states and/or to stratify diseases. It has been proven that the origin of a disease or subtypes/stratification of its condition can be defined by analyzing mRNA expression patterns [3640]. The identification of genes with altered expression or marker genes could also be potential targets for novel and more effective therapy [41].

COPD is a prime example of a long-lasting, chronic disease with devastating outcome with essentially no validated clinical markers or biomarkers other than lung function tests being available. The pathomechanism of COPD has been examined at different levels, such as cell cultures, animal models and primary clinical samples $[18,20-23,42-46]$.

The present study had three major goals: (1) to expand and validate the list of genes associated with COPD in
AMs; (2) to find and validate potential biomarkers in peripheral blood MOs that reflect COPD-specific gene expression patterns identified in AMs as well as their precursors, peripheral circulating MOs, and (3) to correlate gene expression patterns with disease parameters.

To meet these goals, stringent inclusion/exclusion criteria were applied and largely independent sets of patients were used for screening (microarray) and validation (RTqPCR). Our results suggest that gene sets specific for COPD can be identified in both cell types based on their expression patterns.

An important aspect of our work is that in addition to supporting the importance of several previously identified COPD-related genes, e.g. CYP1B1, PLA2G7, CCL2, SPP1, IL-8 and IL-1 $\beta$, we were able to supplement the list of COPD-specific probe sets that are expressed differently in AMs of diseased patients and healthy controls. From this list, 23 genes were validated by RT-qPCR in a larger cohort of independent samples.

The progenitors of the AMs are peripheral blood MOs, which are recruited and differentiated into AMs during physiological processes in control individuals as well as during progression of COPD in diseased patients $[47,48]$. It appeared to be intriguing and important to evaluate the possibility that there are similar COPD-specific changes in the expression of genes in the precursor and the differentiated cells in the controls and COPD patients. The identification of such genes might be used as biomarkers for COPD, which may help in establishing and verifying the diagnosis, and in testing the efficacy of treatment during disease progression or regression. In addition, it would also establish the involvement of MOs in COPD.

We identified commonly expressed genes in AMs and MOs. What we consider as a key aspect of our work is the identification of a set of 5 genes showing common expression patterns in AMs and MOs. It suggests that these two related cell types are both affected in the disease and this is manifested by peripheral gene expression signatures. These genes include PHLDA1, an apoptotic gene that was also validated using AM RNA samples. ADAM10 is a cell surface protein with protease function, which activates TNF $\alpha$ by cleaving its inactive form. Elevated expression of ADAM10 has previously been documented in smokers [22]. IFDR1 is a nervous system-specific gene, which could have a role in proliferative and differentiation pathways induced by nerve growth factor. Higher expression of IFRD1 was observed in lung cancer and other types of cancers. GK is a key enzyme of glycerol metabolism. SEC14L1 is involved in cytosolic transport. Obviously, 
these pathways should be further scrutinized for their involvement in COPD.

It is possible that both cell types are affected by the disease as the result of a secondary effect due to similar systemic (chronic inflammatory) changes resulted in similar alterations. One cannot exclude this possibility. This would also include similar changes in other tissue macrophages. Moreover, similar changes might be found in other chronic inflammatory diseases, such as rheumatoid arthritis, psoriasis or inflammatory bowel disease. A more intriguing and in fact more likely scenario is that preformed changes in the precursor cell type have a causative role in the development of the disease, and that these (primary or secondary) alterations are propagated into differentiated tissue macrophages, such as AMs. Both of these possibilities can and should be tested and their evaluation can lead to important insights into the pathogenesis of COPD and other chronic inflammatory diseases, including the identification of differentiating gene expression profiles and/or markers. It would be particularly intriguing to look at the identified 23 and 5 member gene sets in terms of single nucleotide polymorphisms in order to identify potential genetic changes associated with COPD. In such studies, regulatory regions (single nucleotide polymorphisms) deserve particular attention. At the same time, simply using the gene sets for validating the hypothesis that peripheral MO gene expression can serve as marker of disease progression and maybe therapeutic efficacy would also have clinical insights and benefits.

Previous studies showed a correlation between several single nucleotide polymorphisms and accelerated $\mathrm{FEV}_{1} \%$ decline in COPD [49]. In addition, Woodruff et al. [23] showed that elevated mRNA levels of SPP1 correlated with decreased lung function in smokers compared to non-smokers. Tomaki et al. [50] identified that decreased expression of antioxidant genes correlate with the degree of airflow limitation. Importantly, our results also showed that COPD-specific gene expression signatures of AMs (notably CCR1, FN1, GDF15 and SLC2A3) and MOs (such as ADAM10, GK, IFRD1 and SEC14L1) correlate with $\mathrm{FEV}_{1} \%$, which may suggest that disease progression can be determined and monitored by analyzing either disease-specific or peripheral blood gene expression patterns using a panel of genes.

In summary, we sought to define gene sets showing differential expression patterns between controls and patients in the two cell populations in order to evaluate whether either or both cell types are affected by the disease and if there is an overlap in altered gene expression.
We identified and validated COPD-specific overlapping signatures of expression profiles of peripheral blood MOs and AMs demonstrating that peripheral MOs are also affected by COPD. The discriminating power of the set of 23 genes validated in AM samples and the set of 5 genes validated in MO samples was also present using CVA, which could separate COPD patients and healthy controls in both cases in which the $\chi^{2}$ test of canonical correlation was significant at $p=0.05$, suggesting that the gene lists do have a strong discriminating power even though separation of the two groups was not perfect.

Some of the validated expression changes correlate with lung function. The present data may provide a basis for more mechanistic studies of disease pathomechanisms, and some of the differentially expressed genes may serve as biomarkers of disease progression and response to therapy in the future.

\section{Acknowledgement/Financial Disclosure and Conflicts of Interest}

The authors are indebted to Zsuzsa Bodnár for clinical coordination, Drs. Attila Vaskó, Péter Szabó and Sándor Sz. Kiss, Titanilla Tölgyesi and Mária Ráduly for the help with clinical sample collection and analysis, and Drs. David Loose and András Penyige and members of the Nagy laboratory for their comments. The authors would like to thank the expert technical assistance of Júlia Buslig, Ibolya Fürtös and Marta Béládi.

L.N. is an International Scholar of HHMI and holds a Wellcome Trust Senior Research Fellowship in Biomedical Sciences; this work was also supported by grants from the National Office for Research and Technology (NKFP 1/007/01 and 1A/008/04) and a grant from the Hungarian Scientific Research Fund (NI 67877).

Except for Dr. Iain Kilty, who is director of Pfizer and holder of Pfizer stock, the authors have no conflict of interest to disclose.

References

1 Barnes PJ: Mediators of chronic obstructive pulmonary disease. Pharmacol Rev 2004;56: 515-548.

2 Turato G, Zuin R, Saetta M: Pathogenesis and pathology of COPD. Respiration 2001; 68:117-128.

-3 Mannino DM: Epidemiology and global impact of chronic obstructive pulmonary disease. Semin Respir Crit Care Med 2005;26: 204-210.

4 Reilly JJ: COPD and declining FEV1 - time to divide and conquer? N Engl J Med 2008; 359:1616-1618. 
5 Scanlon PD, Connett JE, Waller LA, Altose MD, Bailey WC, Buist AS: Smoking cessation and lung function in mild-to-moderate chronic obstructive pulmonary disease. The Lung Health Study. Am J Respir Crit Care Med 2000;161:381-390.

6 Hogg JC: Pathophysiology of airflow limitation in chronic obstructive pulmonary disease. Lancet 2004;364:709-721.

7 Barnes PJ, Shapiro SD, Pauwels RA: Chronic obstructive pulmonary disease: molecular and cellular mechanisms. Eur Respir J 2003; 22:672-688.

8 van Eeden SF, Sin DD: Chronic obstructive pulmonary disease: a chronic systemic inflammatory disease. Respiration 2008;75: 224-238.

-9 Stockley RA: Neutrophils and the pathogenesis of COPD. Chest 2002;121:151S-155S.

$\checkmark 10$ Kool M, Lambrecht BN: Dendritic cells in asthma and COPD: opportunities for drug development. Curr Opin Immunol 2007; 19: 701-710.

-11 Shapiro SD: The macrophage in chronic obstructive pulmonary disease. Am J Respir Crit Care Med 1999;160:S29-S32.

-12 Finkelstein R, Fraser RS, Ghezzo H, Cosio MG: Alveolar inflammation and its relation to emphysema in smokers. Am J Respir Crit Care Med 1995; 152:1666-1672.

$\checkmark 13$ Corrigan CJ, Kay AB: The roles of inflammatory cells in the pathogenesis of asthma and of chronic obstructive pulmonary disease. Am Rev Respir Dis 1991;143:1165-1168, discussion 1175-1166.

14 Shapiro SD, Ingenito EP: The pathogenesis of chronic obstructive pulmonary disease: advances in the past 100 years. Am J Respir Cell Mol Biol 2005;32:367-372.

15 Barnes PJ: Mechanisms in COPD: differences from asthma. Chest 2000;117:10S-14S.

16 Barnes PJ: Immunology of asthma and chronic obstructive pulmonary disease. Nat Rev Immunol 2008;8:183-192.

17 Kent L, Smyth L, Clayton C, Scott L, Cook T, Stephens R, Fox S, Hext P, Farrow S, Singh D: Cigarette smoke extract induced cytokine and chemokine gene expression changes in COPD macrophages. Cytokine 2008; 42 : 205-216.

- 18 Spira A, Beane J, Pinto-Plata V, Kadar A, Liu G, Shah V, Celli B, Brody JS: Gene expression profiling of human lung tissue from smokers with severe emphysema. Am J Respir Cell Mol Biol 2004;31:601-610.

$\checkmark 19$ Golpon HA, Coldren CD, Zamora MR, Cosgrove GP, Moore MD, Tuder RM, Geraci MW, Voelkel NF: Emphysema lung tissue gene expression profiling. Am J Respir Cell Mol Biol 2004;31:595-600.
20 Ning W, Li CJ, Kaminski N, Feghali-Bostwick CA, Alber SM, Di YP, Otterbein SL, Song R, Hayashi S, Zhou Z, Pinsky DJ, Watkins SC, Pilewski JM, Sciurba FC, Peters DG, Hogg JC, Choi AM: Comprehensive gene expression profiles reveal pathways related to the pathogenesis of chronic obstructive pulmonary disease. Proc Natl Acad Sci USA 2004;101:14895-14900.

21 Harvey BG, Heguy A, Leopold PL, Carolan BJ, Ferris B, Crystal RG: Modification of gene expression of the small airway epithelium in response to cigarette smoking. J Mol Med 2007;85:39-53.

22 Heguy A, O'Connor TP, Luettich K, Worgall S, Cieciuch A, Harvey BG, Hackett NR, Crystal RG: Gene expression profiling of human alveolar macrophages of phenotypically normal smokers and nonsmokers reveals a previously unrecognized subset of genes modulated by cigarette smoking. J Mol Med 2006;84:318-328.

-23 Woodruff PG, Koth LL, Yang YH, Rodriguez MW, Favoreto S, Dolganov GM, Paquet AC, Erle DJ: A distinctive alveolar macrophage activation state induced by cigarette smoking. Am J Respir Crit Care Med 2005;172: 1383-1392.

24 Meuronen A, Majuri ML, Alenius H, Mantyla T, Wolff $\mathrm{H}$, Piirila P, Laitinen A: Decreased cytokine and chemokine mRNA expression in bronchoalveolar lavage in asymptomatic smoking subjects. Respiration 2008; 75:450-458.

25 Tsuji T, Aoshiba K, Nagai A: Alveolar cell senescence exacerbates pulmonary inflammation in patients with chronic obstructive pulmonary disease. Respiration 2010;80:59-70.

-26 Elias JA, Schreiber AD, Gustilo K, Chien P, Rossman MD, Lammie PJ, Daniele RP: Differential interleukin 1 elaboration by unfractionated and density fractionated human alveolar macrophages and blood monocytes: relationship to cell maturity. J Immunol 1985;135:3198-3204.

27 Covin RB, Brock TG, Bailie MB, PetersGolden M: Altered expression and localization of 5-lipoxygenase accompany macrophage differentiation in the lung. Am J Physiol 1998;275:L303-L310.

28 Melis M, Pace E, Siena L, Spatafora M, Tipa A, Profita M, Bonanno A, Vignola AM, Bonsignore G, Mody CH, Gjomarkaj M: Biologically active intercellular adhesion molecule- 1 is shed as dimers by a regulated mechanism in the inflamed pleural space. Am J Respir Crit Care Med 2003;167:1131-1138.

29 Schulz C, Wolf K, Harth M, Kratzel K, KunzSchughart L, Pfeifer M: Expression and release of interleukin- 8 by human bronchial epithelial cells from patients with chronic obstructive pulmonary disease, smokers, and never-smokers. Respiration 2003;70: 254-261.

- 30 Caruso M, Holgate ST, Polosa R: Adenosine signalling in airways. Curr Opin Pharmacol 2006;6:251-256.
1 Rennard SI: Inflammation and repair processes in chronic obstructive pulmonary disease. Am J Respir Crit Care Med 1999; 160:S12-S16

32 Wang H, Liu X, Umino T, Skold CM, Zhu Y, Kohyama T, Spurzem JR, Romberger DJ, Rennard SI: Cigarette smoke inhibits human bronchial epithelial cell repair processes. Am J Respir Cell Mol Biol 2001;25:772-779.

33 Hardie WD, Piljan-Gentle A, Dunlavy MR, Ikegami M, Korfhagen TR: Dose-dependent lung remodeling in transgenic mice expressing transforming growth factor-alpha. Am J Physiol Lung Cell Mol Physiol 2001; 281:L1088-L1094.

- 34 Richter A, O'Donnell RA, Powell RM, Sanders MW, Holgate ST, Djukanovic R, Davies DE: Autocrine ligands for the epidermal growth factor receptor mediate interleukin- 8 release from bronchial epithelial cells in response to cigarette smoke. Am J Respir Cell Mol Biol 2002;27:85-90.

-35 Oudijk EJ, Nijhuis EH, Zwank MD, van de GraafEA, Mager HJ, Coffer PJ, Lammers JW, Koenderman L: Systemic inflammation in COPD visualised by gene profiling in peripheral blood neutrophils. Thorax 2005;60: 538-544.

36 Sotiriou C, Wirapati P, Loi S, Harris A, Fox S, Smeds J, Nordgren H, Farmer P, Praz V, Haibe-Kains B, Desmedt C, Larsimont D, Cardoso F, Peterse H, Nuyten D, Buyse M, Van de Vijver MJ, Bergh J, Piccart M, Delorenzi M: Gene expression profiling in breast cancer: Understanding the molecular basis of histologic grade to improve prognosis. J Natl Cancer Inst 2006;98:262-272.

37 van 't Veer LJ, Dai H, van de Vijver MJ, He YD, Hart AA, Mao M, Peterse HL, van der Kooy K, Marton MJ, Witteveen AT, Schreiber GJ, Kerkhoven RM, Roberts C, Linsley PS, Bernards R, Friend SH: Gene expression profiling predicts clinical outcome of breast cancer. Nature 2002;415:530-536.

- 38 Talbot SG, Estilo C, Maghami E, Sarkaria IS Pham DK, O-charoenrat P, Socci ND, Ngai I, Carlson D, Ghossein R, Viale A, Park BJ, Rusch VW, Singh B: Gene expression profiling allows distinction between primary and metastatic squamous cell carcinomas in the lung. Cancer Res 2005;65:3063-3071.

-39 Steele MP, Brown KK: Genetic predisposition to respiratory diseases: infiltrative lung diseases. Respiration 2007;74:601-608.

40 Breuer RH, Postmus PE, Smit EF: Molecular pathology of non-small-cell lung cancer. Respiration 2005;72:313-330.

41 Schadt EE, Friend SH, Shaywitz DA: A network view of disease and compound screening. Nat Rev Drug Discov 2009;8:286-295. 
42 Tilley AE, Harvey BG, Heguy A, Hackett NR, Wang R, O'Connor TP, Crystal RG: Down-regulation of the notch pathway in human airway epithelium in association with smoking and chronic obstructive pulmonary disease. Am J Respir Crit Care Med 2009;179:457-466.

43 Kazeros A, Harvey BG, Carolan BJ, Vanni H, Krause A, Crystal RG: Overexpression of apoptotic cell removal receptor MERTK in alveolar macrophages of cigarette smokers. Am J Respir Cell Mol Biol 2008;39:747-757.

-44 Meng QR, Gideon KM, Harbo SJ, Renne RA, Lee MK, Brys AM, Jones R: Gene expression profiling in lung tissues from mice exposed to cigarette smoke, lipopolysaccharide, or smoke plus lipopolysaccharide by inhalation. Inhal Toxicol 2006;18:555-568.
45 Kent LM, Smyth LJ, Plumb J, Clayton CL, Fox SM, Ray DW, Farrow SN, Singh D: Inhibition of lipopolysaccharide-stimulated chronic obstructive pulmonary disease macrophage inflammatory gene expression by dexamethasone and the p38 mitogen-activated protein kinase inhibitor $\mathrm{N}$-cyano- $\mathrm{N}^{\prime}$ (2-\{[8-(2,6-difluorophenyl)-4-(4-fluoro-2methylphenyl)-7-oxo-7,8-dihydropyrido [2,3-d] pyrimidin-2-yl]amino\}ethyl)guanidine (SB706504). J Pharmacol Exp Ther 2009;328:458-468.

46 Aldonyte R, Jansson L, Piitulainen E, Janciauskiene S: Circulating monocytes from healthy individuals and COPD patients. Respir Res 2003;4:11.

47 de Boer WI, Sont JK, van Schadewijk A, Stolk J, van Krieken JH, Hiemstra PS: Monocyte chemoattractant protein 1 , interleukin 8 , and chronic airways inflammation in COPD. J Pathol 2000;190:619-626.
48 Hashimoto S, Nakayama T, Gon Y, Hata N, Koura T, Maruoka S, Matsumoto K, Hayashi $\mathrm{S}$, Abe Y, Horie T: Correlation of plasma monocyte chemoattractant protein-1 (MCP1) and monocyte inflammatory protein- $1 \alpha$ $(\mathrm{MIP}-1 \alpha)$ levels with disease activity and clinical course of sarcoidosis. Clin Exp Immunol 1998;111:604-610.

49 van Diemen CC, Postma DS, Vonk JM, Bruinenberg M, Nolte IM, Boezen HM: Decorin and TGF- $\beta 1$ polymorphisms and development of COPD in a general population. Respir Res 2006;7:89.

50 Tomaki M, Sugiura H, Koarai A, Komaki Y, Akita T, Matsumoto T, Nakanishi A, Ogawa H, Hattori T, Ichinose M: Decreased expression of antioxidant enzymes and increased expression of chemokines in COPD lung. Pulm Pharmacol Ther 2007;20:596-605. 